\title{
Knowledge, attitude and reported practice of primary school teachers on specified school health activities in Danuphyu Township, Ayeyarwaddy Region, Myanmar
}

\author{
Ye Minn Htun ${ }^{1}$, Kay Thi Lwin ${ }^{2}$, Nwe Nwe Oo ${ }^{3}$, Kyaw Soe ${ }^{4}$, Than Tun Sein ${ }^{5}$ \\ ${ }^{1}$ Assistant Lecturer; ${ }^{4}$ Professor, Preventive and Social Medicine Department, Defense Services Medical Academy, Yangon, Myan- \\ mar. ${ }^{2}$ Lecturer, Preventive and Social Medicine Department, University of Medicine (1) Yangon, Myanmar. ${ }^{3}$ Rector, University of \\ Nursing, Yangon, Myanmar. ${ }^{5}$ Honorary Professor, Anthropology Department, Yangon University, Yangon, Myanmar.
}

\begin{abstract}
Schools are important settings for comprehensive health promotion. School exerts the most influence on the lives of children and youth. Schools can play a key role in supporting students' health and, by extension, the health of their families and communities. This school-based cross sectional descriptive study was conducted in Danuphyu Township from June to November, 2012. This study aimed to identify the levels of knowledge, attitude and practice of primary school teachers concerning four school health activities: comprehensive school health education; healthy school environments; prevention and control of communicable diseases; and nutritional promotion and food safety. The sample consisted of 97 teachers from 23 primary schools were randomly selected to participate in the study. A pre-tested structured questionnaire was used as a data collection tool. It was found that $62.9 \%$ of teachers achieved a high level of knowledge scores (mean knowledge score of 39.10 with SD 3.087); 57.7\% had a positive attitude towards school health activities; $52.6 \%$ of teachers achieved high reported practice scores (with mean practice score of 66.07 and SD 4.17); teachers from urban areas, over 50 years of age, and with service duration of 20-24 years, are statistically significantly associated with higher levels of reported practice; teachers with high knowledge and positive attitude scores achieved higher reported practice scores, but these associations are not statistically significant. Overall, over $50 \%$ of the teachers had a high knowledge, a positive attitude and high practice scores relating to school health activities, and this shows that favorable conditions exist at the schools among the teachers for further strengthening the school health program of Myanmar. Enhancing teachers' involvement in school health activities would establish good outcomes of the school health promotion program. Provision of continuous training of teachers in school health would further enhance knowledge of teachers, and would gradually inculcate positive attitudes among them. This would lead towards more involvement of teachers in school health activities.
\end{abstract}

Keywords: School health, knowledge, attitude, practice, Myanmar.

\section{Introduction}

Health is closely interlinked to education. Good health and good education are not only ends in themselves, but also means which provide individuals with the tools to lead productive and satisfying lives. It is commonly believed that a child's ability to attain her or his full potential is directly related to the complimentary effect of good health, good nutrition, physical activity and quality education. ${ }^{1}$ To attain educational achievements, children must fully participate in educational activities. ${ }^{1}$

Children and youth are recognized as a priority population. The national development depends on the academic success and optimal health and well-being of its children and youth. Schools are important settings for comprehensive health promotion. The school exerts the most influence on the lives of children and youth. Schools can play a key role in supporting students' health and, by extension, the health of their families and communities. ${ }^{2-4}$ Studies have also shown that teachers in primary schools can implement an effective health education program for school children. ${ }^{5-9}$

\section{Practice Points}

- Schools are important settings for comprehensive health promotion as they exert the most influence on the lives of children \& adolescents.

- Regarding school health activities, more than $62 \%$ of teachers had a high level of knowledge scores; $57.7 \%$ had positive attitude; and $52.6 \%$ of teachers had high reported practice scores.

- Teachers from urban areas, over 50 years of age, and with service duration of 20-24 years, had significantly higher levels of reported practice.

- High level of knowledge, positive attitude and practice scores indicate that a favorable health promotion environment exists at the schools.

- Further efforts should be take to strengthen school health program to help children be healthier and to increase their educational performance.

Correspondence: Dr Ye Minn Htun, 25-Hinthada Street, Sann-chaung PO, Yangon 11111, Myanmar. E-mail: dryeminnhtun85@gmail.com.

South East Asia Journal of Public Health 2013;3(1):24-29. (C) 2013 Htun et al., publisher and licensee Public Health Foundation Bangladesh. This is an Open Access article which permits unrestricted non-commercial use, provided the original work is properly cited. 
A health promoting school is a setting where education and health programs create a "health promoting" environment which in turn, promotes learning. ${ }^{14}$ Health promoting schools focus on: caring for oneself and others; making healthy decisions and taking control over life's circumstances; creating conditions that are conducive to health; building capacities for peace, shelter, education, food, income, a stable ecosystem, equity, social justice, sustainable development; preventing leading causes of death, disease and disability: helminthes, tobacco use, HIV/AIDS/STDs, sedentary lifestyle, drugs and alcohol, violence and injuries, unhealthy nutrition; and influencing health-related behaviours: knowledge, beliefs, skills, attitudes, values, support. ${ }^{15}$

In Myanmar, the school health services have been implemented since 1921, by the Education Department. ${ }^{10}$ The Ministry of Health is committed to promoting and maintaining the health status of school children through School Health Project in collaboration with Ministry of Education and some other related sectors. The operational unit for rendering comprehensive health care is the Township Health Department, and the participation of school teachers in school health activities in collaboration with health personnel is essential for success of School Health Project in these areas. ${ }^{10}$

School Health Program has been implemented with the objective of promoting the health standard of entire student through health promoting school programme. ${ }^{16}$ All schools are covered with health promoting school program since 2006. Myanmar school-based soil transmitted helminthiasis $(\mathrm{STH})$ control program are gaining momentum with active involvement of related health projects such as School Health Project, Nutrition Project, Maternal and Child Health Project and Lymphatic Filariasis elimination program and Ministry of Education as well as WHO and UNICEF. ${ }^{16}$

It is required to find out the role of teachers in these school health activities and the correlation of their participation to school health activities. This study was conducted with the specific objectives of assessing the levels of knowledge, positive attitude and involvement of teachers relating to school health activities; and determining the association between the school teachers' socio-demographic characteristics, knowledge and attitude with their reported practice in school health activities.

\section{Materials and methods}

\section{Sampling method and procedure}

Figure 1 shows the detailed the conceptual framework of the study. The study was a school based crosssectional descriptive study carried out at primary schools of Danuphyu Township, Ayeyarwaddy Region, Myanmar from June 2012 to November 2012. The study population was the teachers from Primary Schools of Danuphyu Township and sample size was determined based on a study conducted in Myanmar. ${ }^{11}$ Among 163 primary schools in the Township, only 23 schools were selected for the study as these schools had more than five teachers. Four teachers were selected from each of these schools using simple random sampling procedure.

\section{Data collection method and tools}

Quantitative data were collected, after receiving informed consent, by face to face interview method using pre-tested structured questionnaires. The questionnaire included assessment for level of knowledge, attitude towards school health activities and involvement in these activities concerning with promotion and prevention of health of school children. These questionnaires were prepared using 'Manual for School Health, 2005', issued from Department of Health, Ministry of Health, Myanmar, as a reference. ${ }^{13}$

In the first part, there were 10 questions (5 items in each question) for knowledge regarding comprehensive school health education, healthy school environment, prevention and control of communicable diseases and nutritional promotion and food safety. Scoring for the knowledge questions were 1 and 0 ( 1 for correct answer and 0 for incorrect and don't know answers). The second part assessed the attitude of teachers with 12 questionnaires regarding the four specified school health activities. Likert five-point scale was used for scoring and, positive questions and negative questions were included. In the third part, the reported practice of teachers on school health activities was assessed by 31 questionnaires.

\section{Data management and analysis}

At the end of interview, the questionnaires were checked in order to see if there were errors and incompleteness in their answers. Then the responses for questionnaires were coded and the data were entered into the SPSS 16.0 version (Software Package for Social Science). After data entry, data cleaning was done by checking the total frequency and frequency distribution. Outliers and errors were also checked and detected.

Data summarization was done by presenting tables and graphs, and measures of central tendency and measures of dispersion were also calculated. Cross tabulation was done for testing of significance for association between categorical variables, using Chi-square test.

\section{Ethical consideration}

Ethical clearance was obtained from Post Graduate Board of Studies, Defense Services Medical Academy.

\section{Results}

The socio-demographic characteristics of study population are shown in Table 1. Most of teachers were from the rural schools $(69.1 \%)$; females $(91.8 \%)$; in the age range of 22-57 years; Bachelor of Science or Bachelor of Arts graduates (94.8\%); and had less than 15 years service duration (46.4\%).

Table 2 shows that $62.9 \%$ of teachers have high level of knowledge scores, $57.7 \%$ teachers have positive attitude, and $52.6 \%$ of teachers have high reported practice scores. 


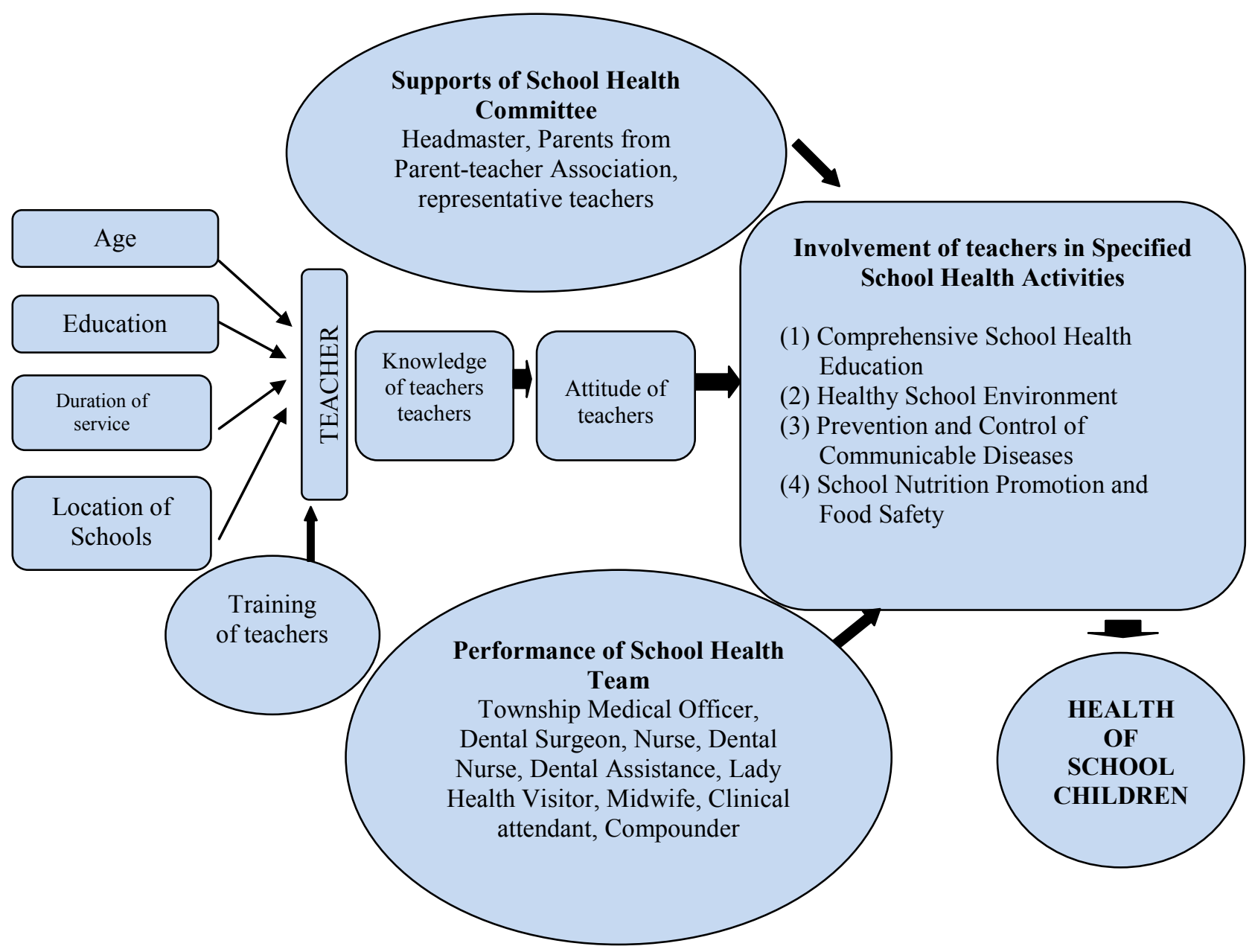

Figure 1: Conceptual framework of the study

Table 3 shows the association between the sociodemographic characteristics, knowledge levels and positive attitude levels of teachers involved in the study, with their reported involvement in school health activities. As shown in Table 3, being teachers from urban areas, over 50 years of age, with service duration of 20 24 years, are found to be statistically significantly associated with higher levels of reported practice. It is also observed that teachers who had high level of knowledge $(57.4 \%)$ were found to be better in reported practice than the teachers who had low level of knowledge (44.4\%). Though it can be assumed that the high knowledge level teacher perform the school health activities more, their association was not statistically significant. Similarly, teachers who had positive attitude $(53.6 \%)$ were found to be better in reported practice than the teachers who had negative attitude $(51.2 \%)$. Thus, it can be assumed that the positive attitude teachers perform the school health activities more. However, their association was not statistically significant.

\section{Discussion}

In this study, we found that $62.9 \%$ (mean knowledge score of 39.10 with SD 3.087) of teachers had high level of knowledge in school health activities, which is higher than the findings $(50.5 \%$; mean knowledge score of 61.5 with SD 10.7) of a previous study ${ }^{12}$ conducted in Myanmar among teachers in Yangon City However, another Myanmar study conducted among school teachers in Mingaladon township revealed higher knowledge level of $(293,76.1 \%)$ the teachers (mean knowledge score of 46.26 with SD 3.2). ${ }^{11}$ The mean knowledge scores of this study are lower than the two previous probably could be due to the two previous studies being conducted in Yangon City and in Mingaladon township which is close to Yangon.

In this study, we found that there were $56(57.7 \%)$ teachers with positive attitude and $41(42.3 \%)$ teachers with negative attitude. In the study by San-San Htway, it was revealed that $277(69.59 \%)$ of the respondents had positive attitude (mean positive attitude score of 30.4 with standard deviation 2.7) ${ }^{12}$ towards school health activities. The study by Win Naing revealed that $217(56.36 \%)$ of the teachers had positive attitude (mean 38.7 with standard deviation 7.2 ) ${ }^{11}$.

This study showed that more teachers $(57.7 \%)$ have positive attitude towards school health activities than the study by Win Naing but lower than the study by San San Htway. As an overall, over $50 \%$ of the teachers in 
Table 1: Socio-demographic characteristics of teachers $(\mathrm{n}=97)$

\begin{tabular}{|c|c|}
\hline Socio-demographic factors & Respondents $(\%)$ \\
\hline \multicolumn{2}{|l|}{ Geographical characteristic } \\
\hline Rural & $67(69.1 \%)$ \\
\hline Urban & $30(30.9 \%)$ \\
\hline \multicolumn{2}{|l|}{ Gender } \\
\hline Male & $8(8.2 \%)$ \\
\hline Female & $89(91.8 \%)$ \\
\hline \multicolumn{2}{|l|}{ Age groups of teachers (year) } \\
\hline$\leq 39$ & $46(47.4 \%)$ \\
\hline $40-49$ & $21(21.6 \%)$ \\
\hline$\geq 50$ & $30(30.9 \%)$ \\
\hline \multicolumn{2}{|c|}{ Mean \pm SD: $(41.46 \pm 10.35)$; range: $22-57$ years } \\
\hline \multicolumn{2}{|c|}{ Education } \\
\hline Graduation & $92(94.8 \%)$ \\
\hline $10^{\text {th }}$ Standard Passed & $5(5.2 \%)$ \\
\hline \multicolumn{2}{|l|}{ Duration of service } \\
\hline$\leq 14$ years & $45(46.4 \%)$ \\
\hline $15-19$ years & $9(9.3 \%)$ \\
\hline $20-24$ years & $15(15.5 \%)$ \\
\hline$\geq 25$ years & $28(28.9 \%)$ \\
\hline Mean \pm SD: $(16.2 \pm 9.1$ & nge: $2-32$ years \\
\hline
\end{tabular}

the three studies having positive attitudes towards school health activities could be interpreted that favorable conditions exist at the schools among the teachers for further strengthening the school health programme of Myanmar.

In this study, the reported practice level was detected with mean 66.07, standard deviation 4.171 and There was $51(52.6 \%)$ teachers with high score level and 46 (47.4\%) teachers with low score level. There were significant associations of level of practice with school location, age and duration of service of teachers. San-San Htway's study revealed that high practice score was achieved by $(223,56.03 \%)$ of teachers (mean reported practice score of 11.4 with SD 4.5$)^{12}$; and that there was a statistically significant difference in practice between the age groups, but no statistically significant difference between different service durations. Win Naing's study revealed that $245(63.63 \%)$ of the teachers achieved high level of practice scores (mean reported practice score of 23.44 with SD 3.7) ${ }^{11}$; that the urban teachers were higher in their levels of practice than the rural teachers, and this association was statistically significant; and statistically significant association between attitude scores of teachers and practice scores.

In this study, $52.6 \%$ of teachers achieved high reported practice scores (with mean practice score of 66.07 and SD 4.17). This shows that in this study, the mean practice score is higher than the mean practice scores of teachers involved in the two previous studies. This signifies that though teachers in Danubyu Township have lower mean knowledge sore, they are practicing more than the teachers in Mingaladon, Yangon City.

The findings of this study showed that teachers having high knowledge and positive attitude on school health play less important than their school location, seniority in age and service duration in determining significant associations with practice.

\section{Conclusion}

As an overall, over $50 \%$ of the teachers having high knowledge, positive attitude and high practice scores relating to school health activities shows that favorable conditions exist at the schools among the teachers for further strengthening the school health program of Myanmar. Enhancing teachers' involvement in school health activities would establish good outcomes of the school health promotion program. Provision of continuous training of teachers in school health would further enhance knowledge of teachers, and would gradually inculcate positive attitudes among them. This would lead towards more involvement of teachers in school health activities.

Studies on knowledge, attitude and practice of school teachers towards school health activities are scarce in Myanmar. Additional similar studies involving primary, middle and high school teachers should be conducted as

Table 2: Levels of knowledge, positive attitude and reported practice relating to school activities among the teachers $(\mathrm{n}=97)$

\begin{tabular}{|l|c|c|}
\hline Level of scores & Respondents $(\%)$ & Mean score (SD; Range) \\
\hline Knowledge & $36(37.1 \%)$ & 39.10 \\
Low (<mean score) & $61(62.9 \%)$ & $(3.087 ; 27-45)$ \\
High ( $\geq$ mean score) & $41(42.3 \%)$ & \\
\hline Attitude & $56(57.7 \%)$ & 66.07 \\
Negative (<mean score) & $46(47.4 \%)$ & $(4.17 ; 52-74)$ \\
Positive $(\geq$ mean score) & $51(52.6 \%)$ & \\
\hline Reported Practice & & \\
Poor $(<$ mean scores) & & \\
Good $(\geq$ mean scores) &
\end{tabular}


Table 3: Association between socio-demographic characteristics, knowledge levels and positive attitude levels of teachers with their reported involvement in school health activities $(n=97)$

\begin{tabular}{|c|c|c|c|}
\hline \multirow[t]{2}{*}{ Characteristics of respondents } & \multicolumn{3}{|c|}{$\begin{array}{l}\text { Reported Practice Level } \\
\text { Respondents }(\%)\end{array}$} \\
\hline & Poor & Good & Total \\
\hline \multicolumn{4}{|l|}{ (1) Socio-demographic characteristics } \\
\hline $\begin{array}{l}\text { Location of Schools* } \\
\text { Rural } \\
\text { Urban }\end{array}$ & $\begin{array}{c}42(62.7 \%) \\
4(13.3 \%)\end{array}$ & $\begin{array}{l}25(37.3 \%) \\
26(86.7 \%)\end{array}$ & $\begin{array}{l}67 \\
30 \\
\end{array}$ \\
\hline $\begin{array}{l}\text { Age group of teachers (in years) } * * \\
\leq 39 \\
40-49 \\
\geq 50\end{array}$ & $\begin{array}{l}28(60.9 \%) \\
10(47.6 \%) \\
8(26.7 \%)\end{array}$ & $\begin{array}{l}18(39.1 \%) \\
11(52.4 \%) \\
22(73.3 \%)\end{array}$ & $\begin{array}{l}46 \\
21 \\
30\end{array}$ \\
\hline $\begin{array}{l}\text { Service duration (in years) } * * \\
\leq 14 \\
15-19 \\
20-24 \\
\geq 25\end{array}$ & $\begin{array}{c}27(60.0 \%) \\
5(55.6 \%) \\
4(26.7 \%) \\
10(35.7 \%)\end{array}$ & $\begin{array}{c}18(40.0 \%) \\
4(44.4 \%) \\
11(73.3 \%) \\
18(64.3 \%)\end{array}$ & $\begin{array}{c}45 \\
9 \\
15 \\
28\end{array}$ \\
\hline $\begin{array}{l}\text { Education } \\
\text { Graduation } \\
10^{\text {th }} \text { Standard Passed }\end{array}$ & $\begin{array}{c}44(47.8 \%) \\
2(40.0 \%)\end{array}$ & $\begin{array}{c}48(52.2 \%) \\
3(60.0 \%) \\
\end{array}$ & $\begin{array}{c}92 \\
5 \\
\end{array}$ \\
\hline \multicolumn{4}{|l|}{ (2) Knowledge } \\
\hline $\begin{array}{l}\text { Low } \\
\text { High }\end{array}$ & $\begin{array}{l}20(55.6 \%) \\
26(42.6 \%)\end{array}$ & $\begin{array}{l}16(44.4 \%) \\
35(57.4 \%)\end{array}$ & $\begin{array}{l}36 \\
61\end{array}$ \\
\hline \multicolumn{4}{|l|}{ (3) Attitude } \\
\hline $\begin{array}{l}\text { Negative } \\
\text { Positive }\end{array}$ & $\begin{array}{l}20(48.8 \%) \\
26(46.4 \%)\end{array}$ & $\begin{array}{l}21(51.2 \%) \\
30(53.6 \%)\end{array}$ & $\begin{array}{l}41 \\
56\end{array}$ \\
\hline
\end{tabular}

*Statistically significant at $\mathrm{p}<0.01$

** Statistically significant at $\mathrm{p}<0.05$

an integral component of monitoring the school health program of Myanmar. The findings should be used for further strengthening school health program to help children be healthier and to enhance their educational outcomes.

\section{References}

1. WHO. Comprehensive school health education, Recommendation and guidelines for implementation and strengthening comprehensive school health education in the South East Asia Region. New Delhi: World Health Organization, 2006.

2. Laforêt-Fliesser Y, Diane FP, Sarah L, Carol MD, Gloria M. School Health Guidance Document (2010), Standards, Programs and Community Development Branch. Ontario: Ministry of Health Promotion, 2010.

3. G. Saraswathy. Report of the National Meeting of the Directors of State Council for Education Research and Training (SCERT) on School Health Promotion (In collaboration with World Health Organization). New Delhi: National Institute of Health \& Family Welfare, 2007.
4. WHO. Global School Health Initiative. http:// www.who.int/entity/school_youth_health/gshi/ en/ (accessed May 2013).

5. Jodkowska M, Oblaciska A, Tabak L, Radiukiewicz K. The role of physical education teachers to support overweight and obese pupils. Med Wieku Rozwoj 2010 ;14(2):197-206.

6. Jourdan D, Pommier J, Quidu F. Practices and representations of health education among primary school teachers. Scand J Public Health 2010 ; 38(1): 86-94.

7. Jourdan D, Stirling, Mannix McNamara P, Pommier $\mathrm{J}$. The influence of professional factors in determining primary school teachers' commitment to health promotion. Health Promot Int $2011 ; 26(3)$ : 302-10.

8. Klepp KI, Ndeki SS, Seha AM, Hannan P, Lyimo BA, Msuya MH, et al AIDS education for primary school children in Tanzania: an evaluation study. AIDS J 1994 ; 8(8): 1157-1162.

9. Petersen PE, Hadi R, Al-Zaabi FS, Hussein JM, Behbehani JM, Skougaard MR, et al. Dental knowledge, attitudes and behavior among 
Kuwaiti mothers and school teachers. J Pedod Spring 1990;14(3): 158-64.

10. MOH. Myanmar National Health Plan (20062011). Yangon: Ministry of Health, 2006.

11. Win-Naing. Role of teachers in School Health in Mingladon Township, Yangon Division in 2008. [thesis] MMedSc (Public Health). Yangon: Defence Services Medical Academy, 2008.

12. San-San-Htway. Perspective of School Teachers on School Health in Yangon Division. [thesis]. MMedSc (Public Health). Yangon: University of
Medicine, 1998.

13. Department of Health. Manual For School Health. Yangon: Department of Health, Ministry of Health, Myanmar, 2005.

14. WHO. A Guide for Establishing Health Promoting School. New Delhi: World Health Organization, Regional Office for South East Asia, 2003.

15. WHO. What is a health promoting school? http:// www.who.int/entity/school_youth_health/en/ (accessed May 2013).

16. MOH. Health in Myanmar 2013. Yangon: Ministry of Health, Myanmar, 2013. 